\title{
Transformation of the Labrador Sea Water in the subpolar North Atlantic
}

\author{
Igor Yashayaev, ${ }^{1}$ Hendrik M. van Aken, ${ }^{2}$ N. Penny Holliday, ${ }^{3}$ and Manfred Bersch ${ }^{4}$ \\ Received 25 August 2007; revised 28 September 2007; accepted 15 October 2007; published 30 November 2007.
}

[1] Development, spreading and decay of the thermohaline properties of two Labrador Sea Water (LSW) classes are described. During the development phase, a specific LSW class repeatedly mixed by winter convection in the Labrador Sea becomes colder, denser, thicker and deeper. Once convection weakens, the LSW class becomes isolated from the upper layer and starts to decay, rapidly losing its volume while retaining the same density due to isopycnal mixing with the neighbouring warm saline intermediate waters. A similar pattern in temperature, salinity and density is seen in the other basins with different time lags from about two years in the Irminger Sea to ten years in the northern Iceland Basin and Rockall Trough regions. The influence of LSW on the thermohaline properties of other North Atlantic water masses is also discussed. Citation: Yashayaev, I., H. M. van Aken, N. P. Holliday, and M. Bersch (2007), Transformation of the Labrador Sea Water in the subpolar North Atlantic, Geophys. Res. Lett., 34, L22605, doi:10.1029/2007GL031812.

\section{Introduction}

[2] The subpolar North Atlantic (SPNA) is an area where the major intermediate and deep water masses of the North Atlantic develop, acquiring their heat, freshwater and other characteristic signatures. The Labrador Sea Water (LSW) is an important component of the North Atlantic Deep Water, contributing to the upper part of the abyssal limb of the meridional overturning circulation (MOC).

[3] Formed by deep winter convection in the Labrador Sea, LSW exports large quantities of fresh water, nutrients and gases (particularly, dissolved anthropogenic gases, e.g. carbon dioxide) from its formation region to the mid-depth layers of the ocean [Clarke and Gascard, 1983; Lazier et al., 2002; Yashayaev, 2007]. Through mixing with the deeper waters its influence extends to the Atlantic abyss, establishing the most effective transoceanic pathway for these and other substances [Yashayaev and Dickson, 2007]. The relatively saline Iceland-Scotland Overflow Water (ISOW, subsequently developing into the Northeast Atlantic Deep Water, NEADW) and the Denmark Strait Overflow Water (DSOW), typically identifiable by the lowest temperatures over the deep water column, arrive from the Arctic and are strongly regulated by Boessenkool et al. [2007] and

\footnotetext{
${ }^{1}$ Bedford Institute of Oceanography, Fisheries and Oceans Canada, Dartmouth, Nova Scotia, Canada.

${ }^{2}$ Royal Netherlands Institute for Sea Research, Den Burg, Netherlands.

${ }^{3}$ National Oceanography Centre, Southampton, UK.

${ }^{4}$ Institute of Oceanography, University of Hamburg, Hamburg, Germany.
}

Copyright 2007 by the American Geophysical Union. 0094-8276/07/2007GL031812 mixed with Yashayaev and Dickson [2007] LSW, which is entirely formed in the SPNA.

[4] LSW hydrography was recently overviewed by Yashayaev [2007] and Yashayaev et al. [2007], discussing two LSW classes developed over the past decades in the Labrador Sea and later found in the Irminger Sea (Figure 1, right) northern Iceland Basin (Figure 2, first and second time-depth plots) and Rockall Trough (Figure 2, third and fourth time-depth plots). The relatively saline and warm intermediate layer separating these two LSW classes within the Labrador and Irminger basins (Figures 1 and 3) is the Icelandic Slope Water (ISW), described by van Aken and de Boer [1995]. At the end of its passage around the subpolar gyre, ISW arrives in the Labrador Sea providing an important source of heat and salt for the mid-depths and partially replacing LSW.

[5] Varying air-sea forcing and hydrographic conditions determine the properties of particular LSW classes. Each LSW class goes through a life cycle of formation and development, spreading and decay. Yashayaev et al. [2007] described the changes of the density structure throughout the life cycle of LSW in its formation region and estimated its transit times through the SPNA. In this paper we focus on the effects of the LSW life cycle on the temperature-salinity structure of the intermediate water in different SPNA basins at different water mass transformation stages.

\section{Data}

[6] The study is focused on two repeated hydrographic sections in the SPNA:

[7] (1) AR7 (Figure 4, map) has been occupied since 1990 primarily by the Bedford Institute of Oceanography (BIO, Fisheries and Oceans, Canada), University of Hamburg (Germany) and Royal Netherlands Institute for Sea Research [Yashayaev et al., 2007];

[8] (2) The northern Rockall Trough has been monitored since 1975 along the Ellett line (named after the founder, David Ellett), and since 1996 the section has been extended to the northern Iceland Basin (Figure 2, map) by the Scottish Association for Marine Science and the National Oceanography Centre, Southampton (UK) [Holliday et al., 2000].

[9] Additionally, we use less systematic but equally important observations of the 1980s from the BIO archives.

\section{Methods}

[10] The methods and approaches used in the current study are described by Yashayaev et al. [2007] and Yashayaev [2007]. 

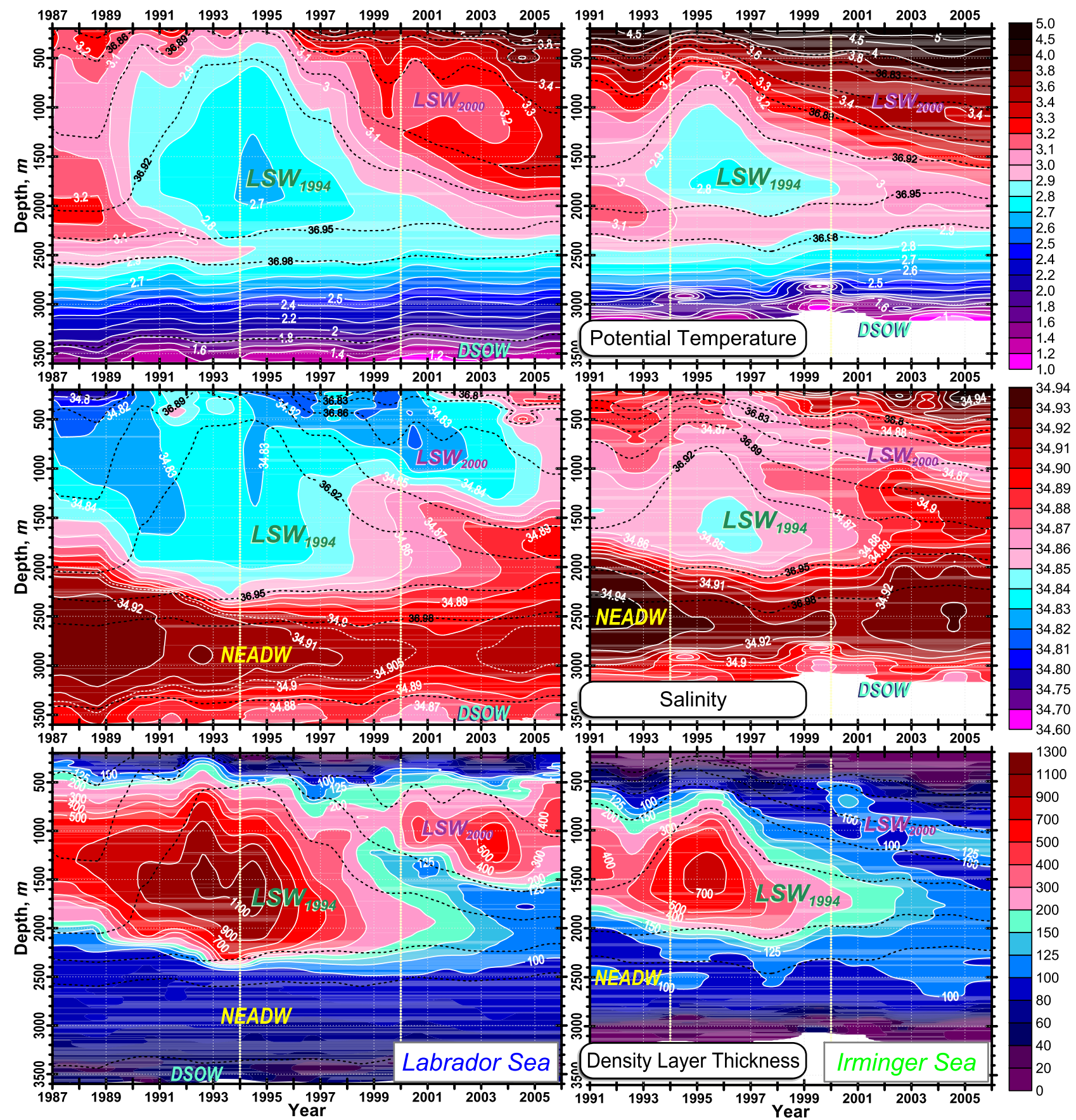

Figure 1. (top) Potential temperature, (middle) salinity, and (bottom) thickness of $\Delta \sigma_{2}=0.01 \mathrm{~kg} \mathrm{~m}^{-3}$ layers (in meters) in the (left) central Labrador (bottom depth $>3250 \mathrm{~m}$ ) and (right) Irminger (bottom depth $>2830 \mathrm{~m}$ ) basins. The hydrographic profiles were first regionally averaged for each survey. LSW became notably denser (see dashed $\sigma_{2}$ isolines) between 1990 and 1994.

\subsection{Full-Depth Changes}

[11] To visualize the temporal evolution of a whole water column we map vertical profiles spatially averaged over individual surveys in time-depth coordinates. Figures 1 and 2 show full-depth changes in the central Labrador and Irminger Seas (1987-2005), and in the Rockall Trough and northern Iceland Basin (1975-2006). The values used in Figures 1 and 2 were formed by robust averaging in density bins (see auxiliary material). ${ }^{1}$

\footnotetext{
${ }^{1}$ Auxiliary materials are available in the HTML. doi:10.1029/ $2007 \mathrm{GL} 031812$.
}

\subsection{Volumetric Methods}

[12] Since LSW is formed by convective mixing, it is characterized by low vertical gradients of seawater properties. This allowed the use of a volumetric census of the density field given by Yashayaev et al. [2007] for defining hydrographic properties of the LSW core, and now justifies the use of a volumetric potential temperature-salinity $(\theta-\mathrm{S})$ analysis for documenting transformations of LSW through a full "life cycle" (production, spreading, mixing) of this water. Both volumetric approaches automatically adjust to 

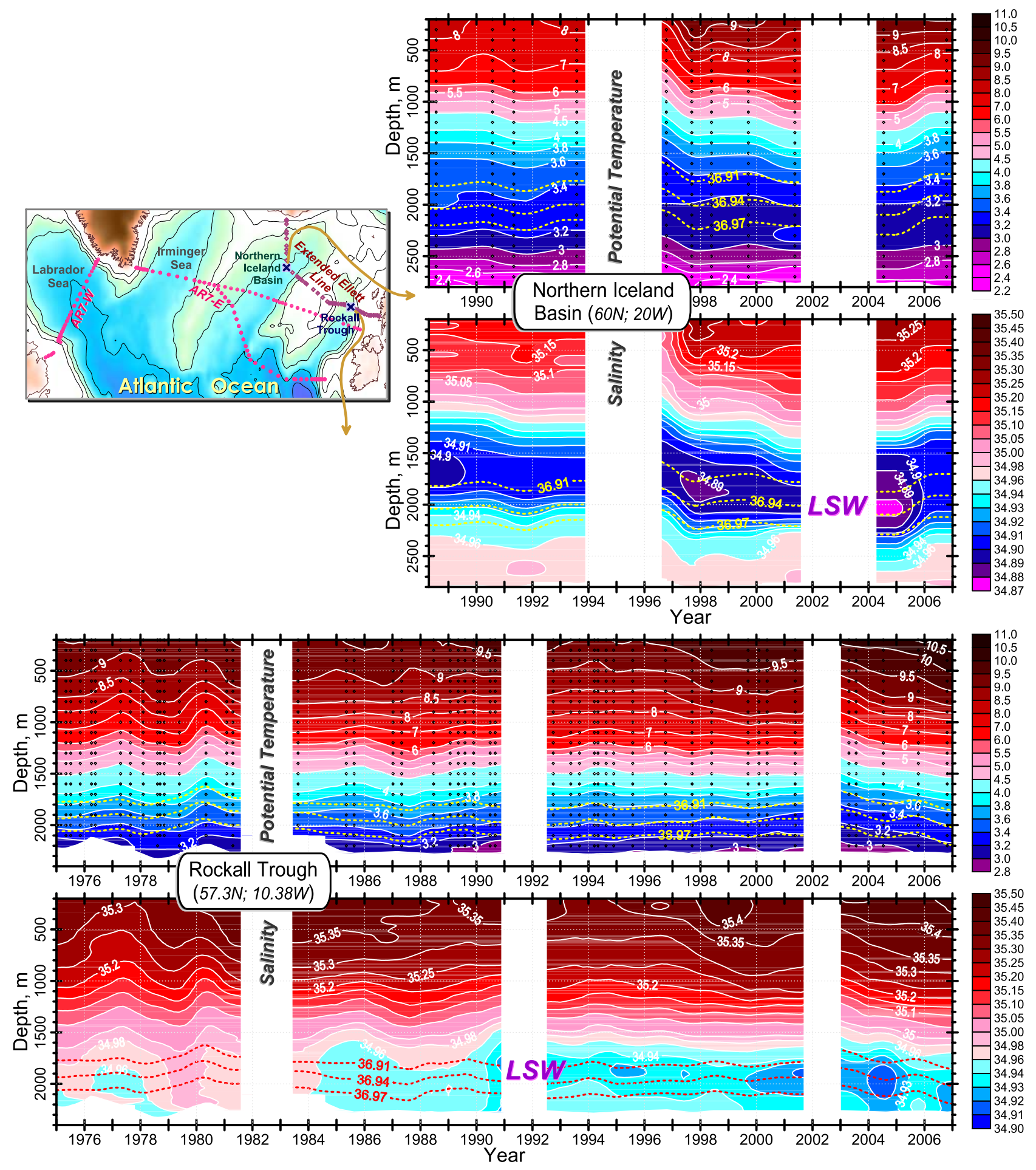

Figure 2. Potential temperature (first and third time-depth plots) and salinity (second and fourth) in the northern Iceland Basin (first and second) and Rockall Trough (third and fourth).

and therefore reveal the interesting changes that occur in LSW.

[13] The $\theta-S$ method is described in the auxiliary material. Figure S1 of the auxiliary material shows selected hydrographic surveys of the Labrador Sea to illustrate the evolution of LSW and other waters; while Figure S2 shows three SPNA basins in the same year, 1995, thus illustrating the spatial variations introduced as the same water masses are advected around the SPNA under the influence of mixing and variable initial "formation" conditions.

\section{3. $\theta$-S Evolution}

[14] Basin-year $\theta$-S curves were constructed from individual volumetric $\theta$-S censuses (auxiliary material). The $\theta-\mathrm{S}$ curves are arranged here (Figure 3 ) by periods representing the progressive development phase of $\mathrm{LSW}_{1987-1994}$ 

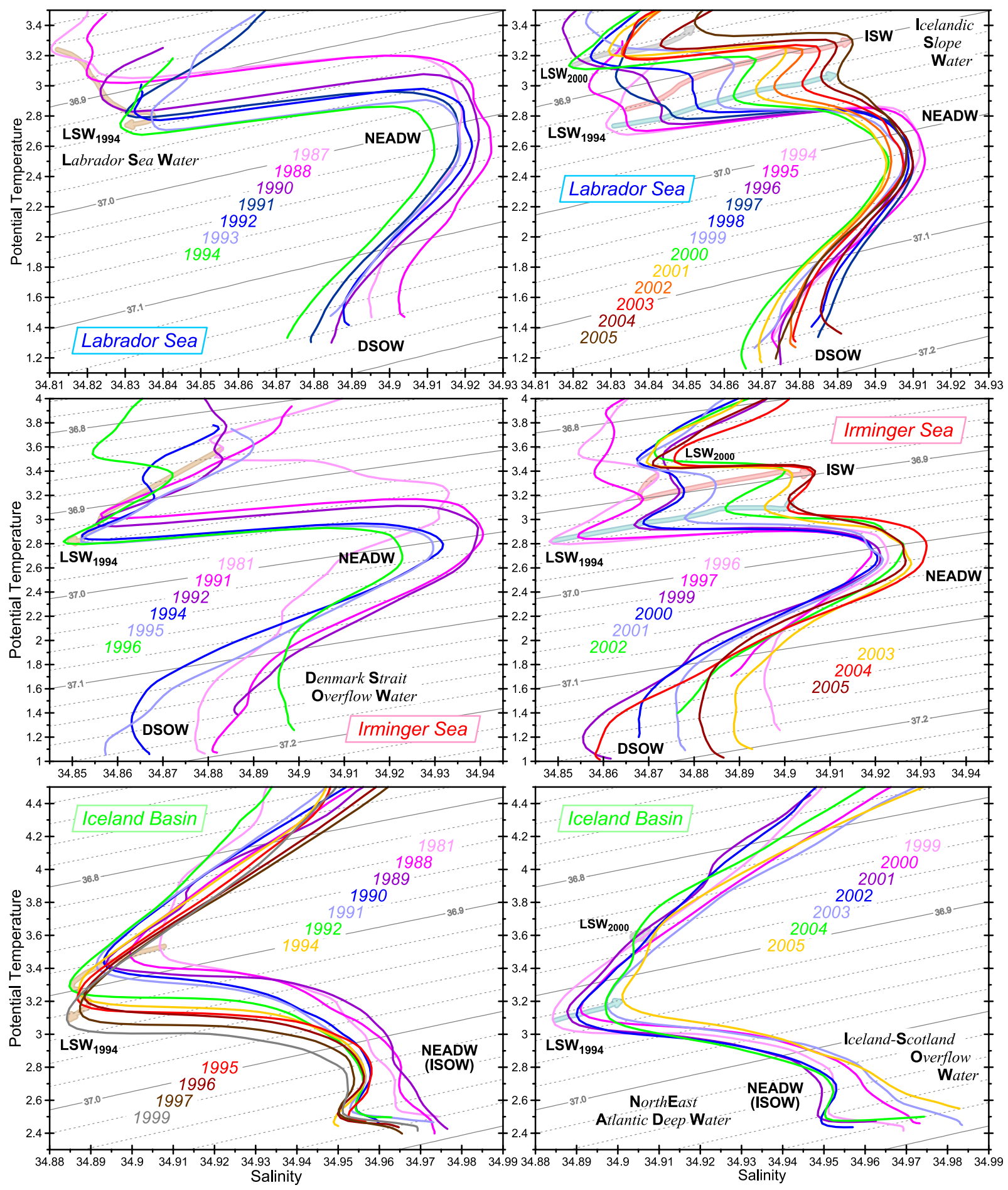

Figure 3. Potential temperature $(\theta)$ vs salinity $(S)$ curves based on volumetric $\theta-S$ analyses of the Labrador Sea (bottom depth $>3250 \mathrm{~m}$ ) for the years (top left) 1987-1994 and (top right) 1994-2005, Irminger Sea (>2500 m) for (middle left) 1981-1996 and (middle right) 1996-2005, and Iceland Basin (>2300 m) for (bottom left) 1981-1999 and (bottom right) 1999-2005. The arrow-headed lines indicate developments and subsequent transformations of $\mathrm{LSW}_{1987-1994}, \mathrm{LSW}_{2000 \text {, }}$ and the warm and salty ISW-derived layer separating the two LSW classes.

(Figure 3, left) and the subsequent transformation phase, characterized by the rapid decay and ultimately the vanishing of this LSW class (Figure 3, right).

[15] The light-colored arrow-headed lines in the background of Figure 3 follow development and transformation (evolution) of LSW and ISW in three subpolar basins.

\subsection{LSW Classes}

[16] LSW cores (volumetric peaks) with a common development and transformation history form a single LSW class. Two LSW classes, LSW $1987-1994$ and $\mathrm{LSW}_{2000}$, were introduced in the previous paper and their 

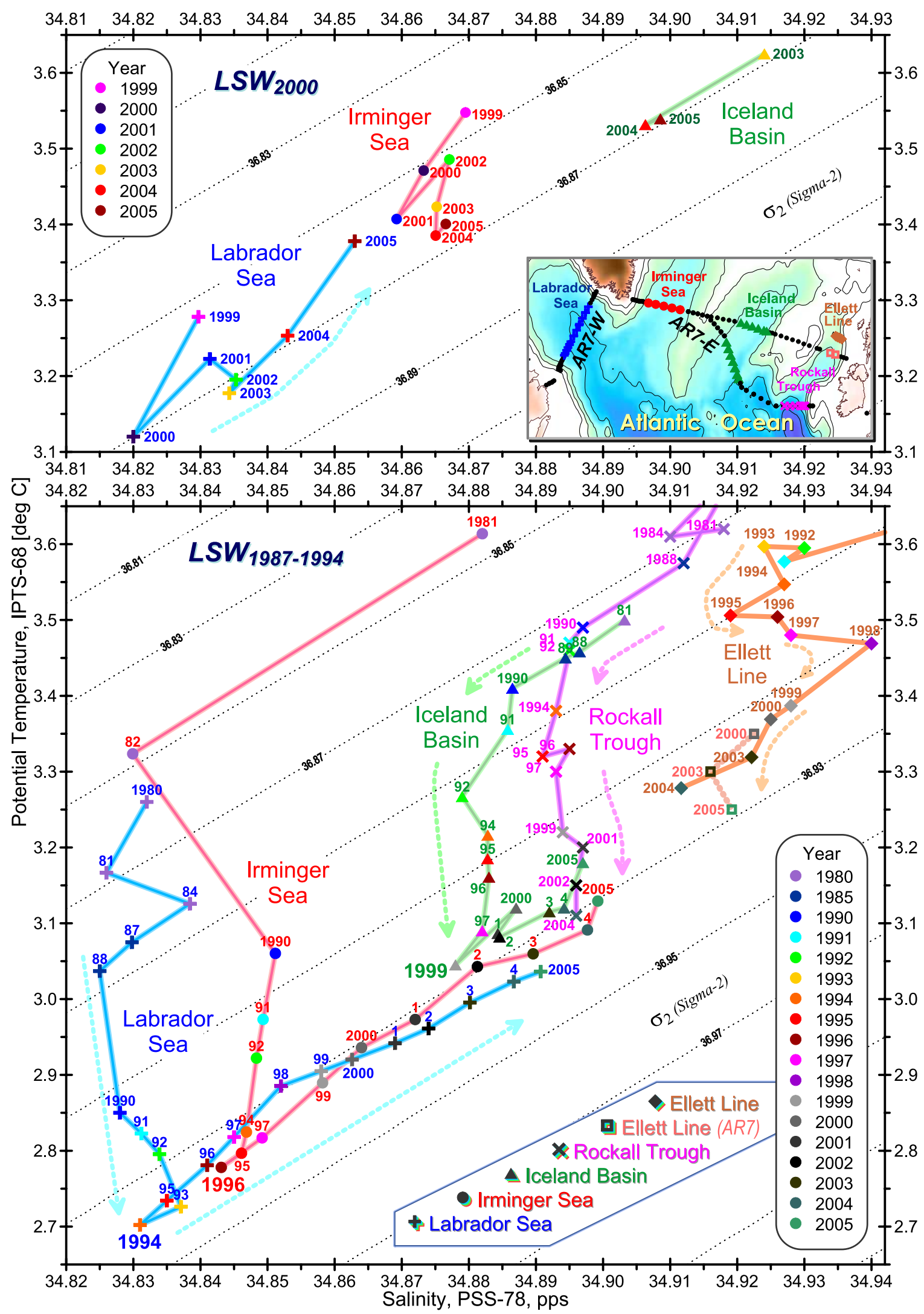

Figure 4. $\theta$-S-time "trajectories" of the (bottom) $\mathrm{LSW}_{1987-1994}$ and (top) $\mathrm{LSW}_{2000}$ classes in the Labrador, Irminger, Iceland, Rockall Trough, and "Ellett Line" basins (left to right), following development, spreading, and transformation of each LSW class indicated by the arrow-headed lines. The dotted contours are $\sigma_{2}\left(\mathrm{~kg} \mathrm{~m}^{-3}\right)$ isolines. 
appearances in the regional water columns (Figures 1 and 2) and $\theta$-S signatures (Figures 3 and 4 ) are discussed here.

[17] Time-depth plots of temperature and salinity in the Labrador and Irminger Seas (Figure 1) show strong interannual to decadal changes in convective mixing and LSW properties in the LSW formation region and the adjacent basin. Similar distributions for the northern Iceland Basin and Rockall Trough (Figure 2) were constructed from hydrographic profiles collected at the deepest repeated stations in these two basins (Figure 2, map).

[18] Regional compilations of annual $\theta$-S curves (Figure 3) demonstrate systematic water mass developments and changes, which, in the case of LSW, can be followed from the Labrador Sea to the Irminger Sea and the Iceland Basin (with associated time lags).

[19] $\theta$-S-time projections of the LSW classes (Figure 4) link the regional LSW evolutions with the LSW source, adding to the recent LSW history.

\section{Rise and Decline of $\mathbf{L S W}_{1987-1994}$}

[20] The LSW $1987-1994$ class was produced by recurring strong winter convection between the mid-1980s and mid1990s [Lazier et al., 2002; Yashayaev, 2007]. Formed through convective cooling and freshening of the Labrador Sea this water was colder, denser, deeper and thicker than its documented predecessors.

[21] An isolated volumetric $\theta$-S maximum appeared in 1987 at $\sigma_{2}=36.885 \mathrm{~kg} \mathrm{~m}^{-3}\left(\sigma_{2}\right.$ is potential density anomaly referenced to the $2000 \mathrm{dbar}$ pressure), subsequently evolving to reach its high level in 1994 at $\sigma_{2}=36.940 \mathrm{~kg} \mathrm{~m}^{-3}$ and thus complete the phase of record-strong water mass production in the Labrador Sea (Figures 1 and 3). Between 1987 and 1994, this LSW became about $0.45^{\circ} \mathrm{C}$ colder and $0.06 \mathrm{~kg} \mathrm{~m}^{-3}$ denser. It nearly doubled in volume, developing into a large homogeneous body of exceptionally cold, fresh and dense water reaching below $2400 \mathrm{~m}$. The LSW layer in the Irminger Sea is typically $\sim 0.1^{\circ} \mathrm{C}$ warmer, $\sim 0.01$ saltier and, at least, a third thinner than in the Labrador Sea. However, these two basins demonstrate very similar changes in the LSW thickness and $\theta$-S characteristics, delayed by $1-2$ years on the Irminger side.

[22] The 1987-to-1993 increase of the LSW $1987-1994$ salinity was maintained in the Labrador Sea by entrainment from below of saltier NEADW into fresher LSW every time that convection deepened (Figure 3, top left). It is also possible that convective entrainment of the warm salty Irminger Sea waters had added extra salt to $\mathrm{LSW}_{1987-1994}$.

[23] $\mathrm{LSW}_{1987-1994}$ shows two consecutive salinity minima: the first minimum came with the initiation of this LSW class in the late 1980s, while the second appeared in the year of its maturity, in 1994 in the Labrador Sea and about two years later in the Irminger Sea (Figure 1). We will revisit these two salinity minima in our discussion of the LSW changes in the northeastern basins (Figure 2).

[24] The progressive development of LSW $_{1987-1994}$ throughout the SPNA is characterised by increasing density because of convective cooling (Figures 3 and 4). The same signature, weaker and delayed by 10 years, can be seen in the Rockall Trough (Figure 4).

[25] Weaker atmospheric forcing in the second half of the 1990s also meant weaker Labrador Sea convection that produced less-dense LSW (Figure 1). After its last major renewal in 1994, the LSW $1987-1994$ class evolved without much interaction with the layers above, rapidly thinning as it drained away from the Labrador Sea, while steadily becoming warmer and saltier (Figures S1, 1, 3, and 4; see also Yashayaev [2007]).

[26] After the LSW $1987-1994$ class achieved its greatest thickness and property anomalies in the Labrador and (approximately two years later) Irminger Seas it started to thin (Figure 1). Such a rapid volume decrease is indicative of uncompensated export (advective loss) of LSW to neighbouring basins during the decay phase, following the phase of progressive development.

[27] The LSW decay is generally characterized by the counterbalanced contributions of temperature and salinity changes to density: the initially increasing density of LSW $1987-1994$ stopped changing in the Labrador Sea in 1994, the Irminger Sea in 1996 and the Iceland Basin in 1999, while both its temperature and salinity started to increase in the same years (Figures 3 and 4).

[28] Between 1994 and 2005, the $\mathrm{LSW}_{1987-1994}$ class became $0.34^{\circ} \mathrm{C}$ warmer and 0.061 saltier in the Labrador Sea. It changed similarly in the Irminger Sea between 1996 and $2005\left(\left.\theta\right|_{2005}-\left.\theta\right|_{1996}=0.34^{\circ} \mathrm{C} ;\left.\mathrm{S}\right|_{2005}-\left.\mathrm{S}\right|_{1996}=0.056\right)$, and by a significantly reduced amount in the Iceland Basin between 1999 and $2005\left(\left.\theta\right|_{2005}-\left.\theta\right|_{1999}=0.14^{\circ} \mathrm{C} ;\left.\mathrm{S}\right|_{2005^{-}}\right.$ $\left.\left.\mathrm{S}\right|_{1999}=0.019\right)$. This large scale warming and salinification of $\mathrm{LSW}_{1987-1994}$ occurred after the cessation of its convective renewal and, as discussed below, was due to isopycnal mixing with warm saline intermediate waters from outside the Labrador Sea (e.g., dense classes of ISW). Recall that during the development of the LSW $_{1987-1994}$ class, the additional salt arriving at different depths and densities was added to it by diapycnal mixing.

[29] The mature and decaying LSW $_{1987-1994}$ class accumulates salt and heat as it spreads away from the Labrador Sea, but retains the same density. This is indicative of the role of isopycnal mixing with warmer and saltier intermediate waters during the post-convective transformation of LSW. If it was not for isopycnal mixing, then a spreading and decaying LSW class would not preserve its density in time and space. Dilution over longer distances and travel times leads to weakening of LSW signals. Indeed, it took about five years for $\mathrm{LSW}_{1987-1994}$ to reach the southern Iceland Basin, and this water arrived there more strongly modified than seen in the Irminger Sea (Figures 3 and 4).

[30] Even after all these years of isolation, accompanied by advective loss and deterioration through enduring mixing, the significantly diminished and transformed $\mathrm{LSW}_{1987-1994}$ class can still be identified as a salinity minimum at $\sigma_{2}=$ $36.935 \mathrm{~kg} \mathrm{~m}^{-3}$ (Figure 3), thus showing a strong resistance to its full dilution. On the other hand, $\mathrm{LSW}_{1987-1994}$ is converging with NEADW in the $\theta$-S space (Figures 1 and 3 ), and we expect that these two water masses will eventually become indistinguishable from each other.

\section{Spreading of $\mathrm{LSW}_{1987-1994}$ to the Northeast Corner of the North Atlantic}

[31] The furthest corners of SPNA reachable by LSW are the northern parts of the Iceland Basin and Rockall Trough. These two basins show similar variability of temperature, 
salinity and homogeneity between 1500 and $2300 \mathrm{~m}$ as the Labrador Sea, but with smaller amplitudes and different mean values, suggesting spreading and modification of the same water. Even though the versions of LSW found in these two regions are more strongly modified and diluted compared to those seen along AR7 (Figures 1 and 3), this water mass can still be unmistakably identified there by its characteristic salinity and/or potential vorticity minima whose $\sigma_{2}$ values (see yellow or red dotted contours in Figure 2) fall within the range of LSW densities in the formation region (Figure 4).

[32] The deep core of the $\mathrm{LSW}_{1987-1994}$ class arriving in the northeast regions of the North Atlantic has been steadily becoming denser through to the present, implying that its densest variant arrived at these two remote destinations just recently. In addition to the $\mathrm{LSW}_{1987-1994}$ density increases matching those seen in the western basins much earlier, each of the two northern corners shows consecutive arrival of two salinity minima separated by $6-8$ years. We suggest that these minima are substantially modified but still identifiable replicas of the two minima recorded in the Labrador Sea between the mid-1980s and mid-1990s. The arrival of the second minimum in the northern Rockall Trough in 2004 gives a transit time to that basin of 10 years. It takes $4-5$ years for LSW to spread northeastward through the narrowing and shallowing Iceland Basin, almost as much as its lengthy passage from the Labrador Sea to the Iceland Basin.

[33] The salinity minima seen in the northern Iceland Basin and Rockall Trough in 1988 and 1990 can be related to the vintages of fairly fresh LSW formed in the second half of the 1970s.

\section{Evolution of $\mathrm{LSW}_{\mathbf{2 0 0 0}}$}

[34] A thick weakly stratified layer reappears in the Labrador Sea in 2000 as the $\mathrm{LSW}_{2000}$ class (Figure 1). This water can be identified by high $\Delta \sigma_{2}=0.01 \mathrm{~kg} \mathrm{~m}^{-3}$ layer thickness, weak density gradients and low vertical stability, temperature and salinity and found at shallower depths and lower densities than the $\mathrm{LSW}_{1987-1994}$ class (Figures S1, 1, and 3). $\mathrm{LSW}_{2000}$ was massively formed in 2000 and continued to develop and deepen over the subsequent years.

[35] The post-production evolution and transit times of $\mathrm{LSW}_{2000}$ are similar to those of $\mathrm{LSW}_{1987-1994}$; both steadily became warmer and saltier. The warming and salting of $\mathrm{LSW}_{2000}$ (Figure 3, light-gray trajectory, top right; and Figure 4) can also be attributed to mixing with warmer and saltier waters from outside the Labrador Sea. Recent convection events could also bring warmer and saltier waters into the $\mathrm{LSW}_{2000}$ layer [Yashayaev, 2007], but the salinity increases observed in the upper $500 \mathrm{~m}$ after 2003 are apparently insufficient to compensate the buoyancy gained by this layer from warming (Figure 1). The same can be said about the Irminger Basin, where $\mathrm{LSW}_{2000}$ became notably deeper between 2001 and 2005 (compare with the Labrador Sea, Figure 1). The accumulation of low density waters in the place of the sinking and draining $\mathrm{LSW}_{2000}$ class increases the potential for a new LSW class to develop that could be less dense than any previous vintage.

[36] The $\mathrm{LSW}_{2000}$ class entered the Iceland basin in 2004 , with the same densities $\left(36.86<\sigma_{2}<36.87 \mathrm{~kg} \mathrm{~m}^{-3}\right)$ as those it had four years earlier in the Labrador Sea. It arrived in the Irminger (Figures 1, 3 (middle), and 4) and Iceland (Figures 3 (bottom) and 4) basins after transit times about a year shorter than those determined for the LSW $_{1987-1994}$. The faster spreading can be explained by the increased strength of the horizontal circulation upward.

\section{Invasion of the Icelandic Slope Water}

[37] The corresponding light-pink arrow-headed lines in Figure 3 (top right and middle right) follow the ISW evolution in the Labrador and Irminger basins. As for the $\mathrm{LSW}_{1987-1994}$ and $\mathrm{LSW}_{2000}$ cores, the core of ISW ( $\sigma_{2}=$ $36.90 \mathrm{~kg} \mathrm{~m}^{-3}$ ) is steadily becoming warmer, saltier and deeper, tending to replace $\mathrm{LSW}_{1987-1994}$, which, in its turn, has substantially drained away, strongly diminished in size and lost much of its contrast with the surrounding waters. While the sinking of the warm and salty ISW-derived layer stopped in 2004, this water mass still continues to become warmer and saltier.

\section{Conclusion}

[38] Life cycles of two LSW classes are described and followed throughout the SPNA.

[39] The first, extremely dense, deep and voluminous LSW $_{1987-1994}$ class was progressively built by intense winter convection in the Labrador Sea during 1987-1994. The signatures of this water mass development (cooling, freshening, increasing density, depth and thickness) are seen in the other subpolar basins with a time lag associated with the spreading of LSW. This we define as the phase of progressive development of the $\mathrm{LSW}_{1987-1994}$ class.

[40] The LSW ${ }_{1987-1994}$ class stopped changing its density and began its decline or decay after the cessation of its convective renewal in the Labrador Sea. During this phase LSW accumulates heat and salt through isopycnal mixing with warm saline intermediate waters originating outside the Labrador Sea. A similar pattern in temperature, salinity and density is seen in the other basins with different time lags. Figure 4 clearly shows the "propagation" of the phase change away from the Labrador Sea. $\mathrm{LSW}_{1987-1994}$ arrived in the Irminger Sea about two years after its formation, in the Iceland Basin after five years, and in the Rockall Trough and northern Iceland Basin after at least a decade.

[41] Most of LSW $1987-1994$ has already left the SPNA, but its remnants can still be seen there.

[42] Since LSW contributes to NEADW, its signals are expected to affect the properties of NEADW. This explains why the time passed between the reversals of freshening in LSW and NEADW increases as one moves from the Irminger Sea to the Labrador Sea (Figure 1). NEADW reversed its freshening trend in 2000 in the Irminger Sea, and in 2001-2002 in the Labrador Sea. So we note that the salinity minimum in NEADW follows that in $\mathrm{LSW}_{1987-1994}$ by about 5 years in the Irminger Sea and 10-12 years in the Labrador Sea, agreeing with the water mass spreading history. Indeed, LSW enters the Iceland Basin about 5 years after its formation, mixes into ISOW and 5-8 years later returns to the Labrador Sea as a component of NEADW [Yashayaev and Dickson, 2007], suggesting a time lag of $10-13$ years. 
[43] The second, shallower less dense $\mathrm{LSW}_{2000}$ class gained strength in 2000, and became even thicker and deeper over subsequent years. The distributions of $\mathrm{LSW}_{2000}$ thickness and properties indicate that this water originated in the coldest and freshest region of the SPNA, the Labrador Sea.

[44] The recent restratification and buoyancy build-up made a winter renewal of $\mathrm{LSW}_{2000}$ very unlikely. Will $\mathrm{LSW}_{2000}$ become fully isolated from the upper layers? Will deep convection re-ventilate the waters below $2000 \mathrm{~m}$ again, but at lower densities? Several years will pass before we will be able to answer these important questions, but now we at least anticipate further arrival and transformation of $\mathrm{LSW}_{2000}$ in the eastern basins.

[45] In contrast to the deep LSW layer in the eastern basins, the upper layers of the northern Rockall Trough and Iceland Basin regions show extraordinarily high warming and salinification since the mid-1990s (Figure 2). Similar increases in temperature and salinity are being observed in the upper layers of the Irminger and Labrador Seas (Figure 1). Our knowledge of the cyclonic nature of the subpolar gyre suggests that these temperature and salinity increases in the upper $1000 \mathrm{~m}$ layer of the eastern basins are an upstream source of additional heat and salt for the Labrador Sea. However it is not clear which other large-scale or local processes are now contributing to the upper layer changes in the Labrador Sea. Whatever the source of additional heat and salt, it is clear that they are collectively affecting and shaping upcoming LSW developments.

[46] Acknowledgments. The authors thank Dan Wright for valuable comments and suggestions, Allyn Clarke, David Ellett, John Lazier, Jens Meincke, Detlef Quadfasel and others who over several decades surveyed the subpolar North Atlantic. Fisheries and Oceans Canada (DFO) at the
Bedford Institute of Oceanography is gratefully acknowledged for its ongoing support of oceanographic surveys of the Labrador Sea under its Ocean Climate Monitoring program.

\section{References}

Boessenkool, K. P., I. R. Hall, H. Elderfield, and I. Yashayaev (2007), North Atlantic climate and deep-ocean flow speed changes during the last 230 years, Geophys. Res. Lett., 34, L13614, doi:10.1029/2007GL030285.

Clarke, R. A., and J.-C. Gascard (1983), The formation of Labrador Sea Water. Part I: Large-scale processes, J. Phys. Oceanogr., 13(10), $1764-$ 1778 .

Holliday, N. P., R. T. Pollard, J. F. Read, and H. Leach (2000), Water mass properties and fluxes in the Rockall Trough: 1975 to 1998, Deep Sea Res., Part I, 47(7), 1303-1332.

Lazier, J. R. N., R. M. Hendry, R. A. Clarke, I. Yashayaev, and P. Rhines (2002), Convection and restratification in the Labrador Sea, 1990-2000, Deep Sea Res., Part I, 49(10), 1819-1835.

van Aken, H. M., and C. J. de Boer (1995), On the synoptic hydrography of intermediate and deep water masses in the Iceland Basin, Deep Sea Res., Part I, 42(2), 165-189.

Yashayaev, I. (2007), Hydrographic changes in the Labrador Sea, 19602005, Prog. Oceanogr., 73(3-4), 242-276, doi:10.1016/j.pocean. 2007.04.015.

Yashayaev, I., and R. R. Dickson (2007), Transformation and fate of overflows in the northern North Atlantic, in Arctic-Subarctic Ocean Fluxes: Defining the Role of the Northern Seas in Climate, edited by R. R. Dickson et al., chap. 21, Springer, New York, in press.

Yashayaev, I., M. Bersch, and H. M. van Aken (2007), Spreading of the Labrador Sea Water to the Irminger and Iceland basins, Geophys. Res. Lett., 34, L10602, doi:10.1029/2006GL028999.

M. Bersch, Institute of Oceanography, University of Hamburg, Bundestrasse 53, D-20146 Hamburg, Germany. (bersch@ifm.unihamburg.de)

N. P. Holliday, National Oceanography Centre, Southampton SO14 3ZH, UK. (nph@noc.soton.ac.uk)

H. M. van Aken, Royal Netherlands Institute for Sea Research, P.O. Box 59, NL-1790 AB Den Burg, Netherlands. (aken@nioz.nl)

I. Yashayaev, Bedford Institute of Oceanography, Fisheries and Oceans Canada, 1 Challenger Drive, P.O. Box 1006, Dartmouth, NS, Canada B2Y 4A2. (yashayaevi@mar.dfo-mpo.gc.ca) 